\title{
Mudanças nas práticas docentes no contexto da inserção de laptops numa escola de ensino fundamental ${ }^{1}$
}

\author{
Eliana Maria Sacramento Soares ${ }^{2}$ \\ Rosane Kohl Brustolin ${ }^{3}$
}

\section{Resumo}

Apresentamos resultados de um estudo cujo foco foi entender como os professores estão mudando suas práticas no contexto da inserção de laptops na modalidade 1:1, numa escola municipal de ensino fundamental. O objeto de pesquisa foi constituído por dados gerados por meio de entrevista com grupo focal. $\mathrm{O}$ corpus foi tratado segundo a análise textual discursiva em movimentos de unitarização e de categorização. Esse processo permitiu inferir que existem movimentos precursores da constituição de uma nova forma de atuar entre professores e seus estudantes em acoplamento estrutural. Na medida em que os professores se observam e pensam em seu operar em acoplamento com o outro colega, com os estudantes e com a tecnologia, eles se modificam, em congruência com seu operar e em acoplamento com seu domínio de ação.

Palavras-chave: Convivência. Acoplamento estrutural. Mudanças nas práticas docentes. Laptop educacional.

1 Este artigo apresenta resultados de um estudo que é um recorte da pesquisa "Formação humana de educadores no contexto da cultura digital: a inserção do laptop educacional na escola", apoiada pelo CNPq, na chamada $\mathrm{CNPq} / \mathrm{CAPES} \mathrm{N}{ }^{\circ} 07 / 201$.

2 Doutora em Metodologia do Ensino Superior pela Universidade Federal de São Carlos (1997). Pesquisadora e professora do Centro de Ciências Exatas e da Tecnologia da Universidade de Caxias do Sul, RS.

3 Mestre em Educação. 


\title{
Changes in teachers' actions in the context of inserting laptops in a public primary school
}

\begin{abstract}
We present results of a study in which the focus was to understand how teachers are changing their actions, in the context of using laptops in 1:1 mode, in a public primary school. The object of research was constituted by data generated from an interview with focal group. The corpus was treated according to textual discourse analysis and in unitization and characterization movements. This process allowed to infer that there are precursor movements of the constitution of a new way of acting among teachers and students in structural coupling. As far as teachers observe themselves and think about their way of acting together with a colleague, with students, and with technology, they modify themselves according to their way of operating and coupling with their domain of action.
\end{abstract}

Keywords: Living together. Structural coupling. Changes in teacher practices. Educational Laptop.

\section{Introdução}

A relação entre os processos educativos e as tecnologias digitais será aquilo que construiremos a partir da capacidade de constituirmos, com ela, domínios de aprendizagem e contextos existenciais de valor para a vida humana. Dependendo da forma como esse relacionamento acontecer, a inserção das tecnologias digitais nos processos educativos pode ser um fator que desencadeia um processo de redimensionamento das práticas pedagógicas vigentes. Esse redimensionamento, por sua vez, pode levar professores e estudantes a se apropriarem das tecnologias e de suas linguagens para que elas possam ser inseridas não apenas como recursos e ferramentas (material didático), mas, principalmente, 
também como possibilitadoras da emergência de novos domínios de aprendizagem.

Muitas das ações implementadas para a formação de professores no contexto digital nem sempre provocam mudanças significativas em sua prática. Soares e Luciano (2004), tendo como base a Biologia do Conhecer ${ }^{4}$ para explicar suas inferências, enfatizam que o professor precisa ser observador do próprio processo para realizar mudanças estruturais, redimensionando sua prática para pensar o uso das tecnologias digitais.

Além disso, as reflexões teóricas apresentadas pelas autoras sugerem que mudanças precisam ser sustentadas pela parceria e pela convivência, até que os sujeitos professores se sintam seguros e com autonomia para continuarem no fluxo das mudanças, atuando de acordo com suas novas estruturas, constituindo-se num observador de si próprio.

No Brasil, o Programa Nacional de Informática na Educação (Proinfo) tem implantado vários projetos de inserção digital, dentre eles, o "Um Computador por Aluno (UCA), no modelo 1:1", que ofereceu oportunidade para se transformar a prática escolar. A ideia era envolver alunos e professores das escolas contempladas no projeto em práticas que privilegiassem a interação e a cooperação.

A modalidade ou modelo 1:1, como se refere o documento do Proinfo 5 , diz respeito à forma como cada estudante acessa seu laptop em sala de aula para as práticas educacionais. Nesse caso, cada um tem seu laptop para as atividades propostas, diferente de situações nas quais eles se dirigem aos laboratórios, onde alguns usam um mesmo computador, ou quando o professor usa um computador ligado a um projetor para mostrar a tela aos estudantes que, nesse caso, apenas observam alguém usando o recurso.

Nessa modalidade, o estudante pode assumir uma atitude mais ativa. Antes, as tecnologias digitais, representadas por computadores ligados à rede ou com softwares educativos, estavam num laboratório, muitas

\footnotetext{
4 Biologia do Conhecer ou Biologia da Cognição: teoria que amplia o olhar sobre a ontogenia dos seres cognoscentes. Focada sobre processos e fluxos, ao invés de estados e coisas, sua abordagem prioriza o devir, de maneira que o conhecer emerge a partir do viver e da auto-organização dos seres.

5 Disponível em: <http://www.fnde.gov.br/programas/programa-nacional-de-tecnologia-educacional-proinfo/ proinfo-projeto-um-computador-por-aluno-uca $>$.
} 
vezes distante da sala de aula e das práticas cotidianas dos estudantes, presentes em eventuais planejamentos dos professores. Agora, nessa modalidade, os estudantes têm acesso simultâneo a informações, podendo comunicar-se em rede. Surgem novas possibilidades para a aprendizagem, assim como novas demandas para os professores em termos de saberes, planejamento e manejo em sala de aula.

Soares, Pescador e Valentini (2013), analisando a inserção de laptops na escola, argumentam que projetos como o UCA podem se constituir em oportunidade para professores redimensionarem suas práticas, a fim de que incluam, na organização de suas atividades pedagógicas, ações em que os estudantes possam utilizar os laptops conectados à internet de forma colaborativa, favorecendo o surgimento de interações voltadas para a construção da aprendizagem. Caso contrário, enfatizam as autoras, a inserção dos laptops será apenas uma forma de instrumentação, e não uma oportunidade para que as práticas educativas sejam redimensionadas.

Diante dessas considerações, e para contribuir com as discussões em torno do tema, realizamos um estudo que teve como norteadora a seguinte questão: como os professores estão mudando suas práticas no contexto da inserção de laptops na modalidade $1-1^{6}$ numa escola municipal de ensino fundamental?

Para desenvolver o estudo, partimos de alguns aportes da Biologia do Conhecer, pois entendemos que eles oferecem instrumentos conceituais que possibilitam construir uma resposta explicativa para a questão de pesquisa considerada.

\section{Quadro teórico}

Partimos do pressuposto de que, para se pensar em estratégias pedagógicas na inserção digital, é preciso considerar algo que ultrapasse apenas a introdução da tecnologia digital naquilo que já vem sendo feito, mas principalmente entender como as práticas podem ser redimensionadas com a sua presença. Isso significa entender como

6 Neste texto, sempre que utilizarmos a expressão "laptop", estaremos nos referindo a laptop na modalidade $1: 1$, conforme conceituado. 
novas alternativas para o uso desses recursos podem surgir a partir da interação entre os sujeitos envolvidos no contexto escolar, modificado com a presença dos recursos tecnológicos.

Assim, consideramos que os laptops podem propiciar a emergência de espaços sociais, os quais se constituem principalmente das interações sociocognitivas sobre ou em torno de um objeto de conhecimento. Nesse espaço, os sujeitos interagem mediados pela linguagem, cuja interface gráfica/digital do laptop se apresenta como outro elemento na relação entre professores e estudantes. No entanto, o foco não é a interface em si mesma, mas aquilo que os interagentes fazem com essa interface e aquilo que essa interface "faz" com os interagentes, no sentido dos acessos a informações, a processamentos e a simulações por ela possibilitadas.

Sob essa perspectiva, o plano pedagógico que sustenta a concepção e a configuração das práticas no contexto digital é fundamental para que elas possam ser precursoras de um processo cujos interagentes se construam como elementos ativos e coautores, ao mesmo tempo. Plano este que carece de fundamentação teórica sobre a aprendizagem que, por sua vez, inspire práticas pedagógicas potencializadoras da construção do conhecimento.

No arcabouço teórico da Biologia do Conhecer, a aprendizagem é entendida como mudanças estruturais que decorrem de interações recorrentes. Ou seja, os fluxos de interação constituem a rede de comunicação que pode potencializar a aprendizagem, nesse caso, manifestada em mudanças e transformações que ocorrem no contexto de vida de estudantes e professores.

Dessa forma, mudanças estruturais podem ocorrer quando a estrutura do sujeito estabelece correspondência mútua e dinâmica com o meio, possibilitando que ocorra um domínio de estados e um domínio de perturbações em sua estrutura, que lhe permita operar recorrentemente no ambiente de sua atuação por meio de um processo denominado de acoplamento estrutural. Acoplamento estrutural é "a correspondência do espaço temporal efetiva entre as mudanças de estado do organismo e as mudanças recorrentes de estado do meio, enquanto o organismo permanece autopoiético" (MATURANA, 2002, p. 142). 
A deriva das operações realizadas pelos professores no contexto da inserção dos laptops pode provocar mudanças estruturais, a partir de ações recursivas que realizam na convivência. Aquelas que, efetivamente, provocam mudanças podem resultar em aprendizagens advindas de transformações estruturais que se manifestam na conduta: nos modos de agir, de interagir, de conviver e de pensar. É dessa forma que mudanças podem resultar de um processo de interações recorrentes (MATURANA, 2002).

Então, agentes externos ao sujeito, no caso, atividades possibilitadas pelo e no ambiente de inserção dos laptops podem determinar mudanças estruturais, se elas desencadearem processos de redimensionamento interno nos sujeitos envolvidos. Processos estes que são gerados pela estrutura interna de professores, significando que, por mais que os elementos presentes no ambiente instiguem os sujeitos, o que ocorrerá com eles dependerá de como suas estruturas são perturbadas, e assim, somente elas podem determinar uma transformação. Como bem diz Maturana, "vejo a aprendizagem, como um processo de adaptação, de acomodação a uma circunstância diferente daquela em que o organismo (sujeito) se encontrava originalmente" (MATURANA, 1993, p. 31).

Nesse contexto explicativo, entender como estão acontecendo mudanças nas práticas pedagógicas no cenário de inserção dos laptops é mapear o processo dinâmico de acoplamento estrutural entre os sujeitos envolvidos e o laptop, buscando explicitar o historial de interações recorrentes entre os sujeitos: identificar como acontece a convivência entre professores e estudantes numa determinada circunstância, nesse caso, o domínio da sala de aula permeada pela presença dos laptops.

A convivência poderá ser percebida na sala de aula permeada pelos laptops se professores e estudantes se modificarem de forma congruente; o meio produzirá mudanças na estrutura desses sujeitos que, por sua vez, agem sobre ele, alterando-o, numa relação circular: acoplamento estrutural. As mudanças estruturais podem ocorrer quando eles estabelecem interações mútuas e dinâmicas com o meio (no caso, a sala de aula, o laptop e o objeto de conhecimento), o que lhes permitirá operar recorrentemente. Então, as possíveis modificações que acontecerem nas 
estruturas desses sujeitos em convivência resultarão de uma coerência operacional, do operar deles em acoplamento, por meio de interações recorrentes.

Várias pesquisas buscam compreender/explicar os processos de aprendizagem que acontecem em contextos de inserção digital. Beiler (2004) mostra que a aprendizagem pode ser gerada a partir do operar em redes de conversação, em um ambiente constituído por Tecnologias da Informação e Comunicação (TICs). A referida pesquisadora estuda a rede conversacional do fórum de uma disciplina de determinado curso buscando identificar coordenações consensuais de ações, através do desenvolvimento de proposição explicativa que permite analisar os modos de operar das mensagens dos integrantes da comunidade. Tal metodologia permite mapear os modos de estrutura do conversar dos conceitos discutidos, bem como indicar que, através da discussão de conceitos particulares, acontece a construção do conceito mais geral por parte do grupo.

Maraschin e Axt (2005) sustentam a ideia de que as redes conversacionais, suportadas por tecnologias da informação e da comunicação, podem facilitar interações de reconhecimento e de convivência com modos de viver e de pensar distintos dos tomados como próprios, ampliando a possibilidade de produção de deslocamentos dos pontos de vista dos participantes.

Resultados de alguns estudos consideram que, em muitos casos, a presença das tecnologias digitais nas práticas tem levado a pseudoinovações, reduzindo a inserção desses artefatos à mera otimização de práticas pedagógicas tradicionais (FAGUNDES, L. C.; VALENTINI, C. B.; SOARES, E. M. S., 2010; LOPES, D. Q.; VALENTINI, C. B., 2012). Existe unanimidade entre as reflexões desses autores, quando reiteram a necessidade de novas perspectivas para essas práticas.

Fagundes, Valentini e Soares (2010) argumentam que a inserção das tecnologias no processo educativo pode ser perturbadora, no sentido de que estudante e professor estão diante de um elemento novo no cenário da sala de aula. Nessa perspectiva, elas fazem considerações sobre o modo como a sala de aula se modifica, tanto do ponto de vista 
de sua organização física quanto dos fluxos de comunicação entre professor, estudante e objeto de conhecimento. A recomendação que as pesquisadoras fazem é que essas tecnologias não sejam apenas ferramentas ou acessórios a serem utilizados em momentos isolados do processo educativo, mas que sejam principalmente elemento catalisador de mudanças nas práticas docentes e na cultura escolar vigentes.

Seguindo essa linha, Schlemmer (2010) considera que, no contexto da docência, é fundamental transformar a forma de pensar o processo educativo, pois este carece de invenção, de criatividade, de novas formas de trabalho e de novas metodologias. A mesma autora vincula a formação docente à emancipação digital cidadã, entendida como:

[...] um nível tal de apropriação, de fluência tecnológica digital, de forma a propiciar ao sujeito ser um cidadão deste tempo, conferindo-lhe um empoderamento que possibilite exercer a autonomia social e a autoria criativa, num espaço dialógico, cooperativo, perpassado pelo respeito mútuo e pela solidariedade interna, um espaço onde o outro é reconhecido como um outro legítimo na interação e, portanto, alguém com quem é possível estabelecer uma relação em que, em diferentes momentos, ambos são coensinantes e coaprendentes, num processo de mediação e intermediação pedagógica múltipla e relacional, o que permite libertar os sujeitos das relações de opressão, num espaço onde, por meio de um viver e conviver digital virtual, todos se transformam mutuamente por meio das interações que conduzem ao diálogo autêntico. (SCHLEMMER, 2010, p. 107).

Soares e Valentini (2013) ressaltam que a inserção dos laptops, pelo projeto UCA, numa escola municipal provocou a reconfiguração da sala de aula em algumas situações e a emergência de novas configurações de relações interpessoais entre estudantes e professores. Indicam ainda que o processo pedagógico tende a sair, em alguns momentos, do foco do discurso do professor, abrindo novas possibilidades de interação em rede, e que estudantes e professores participam mais ativamente do processo educativo, atuando em convivência. As autoras relatam ainda algum tensionamento entre os domínios de ação do professor e do aluno, uma vez que o professor, em alguns casos, tem dificuldade de sair de seu papel de controle, diante de estudantes que estão se constituindo 
em movimentos de exploração, questionamentos e interação (SOARES; VALENTINI, 2013).

Os resultados que as pesquisas que relacionamos apresentam revelam diferentes movimentos das ações de professores e de estudantes, buscando alternativas para suas práticas em cenários nos quais a tecnologia digital se inclui no processo educativo. Nosso estudo busca, no mesmo sentido, entender como esse movimento acontece num contexto onde o laptop na modalidade 1:1 parece propiciar novas relações, na medida em que cada estudante, ao ter acesso à interface gráfica, de forma individual, pode configurar amplas possibilidades de reorganização das práticas vigentes.

\section{Percurso metodológico}

Os dados para se construir uma resposta à pergunta de pesquisa proposta foram gerados por meio de entrevista com grupo focal, numa escola municipal de ensino fundamental com a inserção de laptops na modalidade 1:1, do programa UCA, no estado do Rio Grande do Sul.

O grupo focal ocorreu em setembro de 2012, com seis professores das áreas: séries iniciais, Língua Portuguesa, Artes e Biologia. Essa escolha obedeceu aos seguintes critérios: possibilidade de estar presente na entrevista, considerando-se a agenda de cada um; diversidade de atuação; uso de laptops em sala de aula. Todas eram professoras com formação superior, com exceção de uma. A faixa etária das entrevistadas variava entre 30 e 50 anos.

Optamos por entrevistas com escuta sensível em grupos focais, por entendermos que elas permitem obter informações por meio de diálogo e conversação; e, sendo assim, articula-se ao quadro teórico escolhido. Conforme reforçam Neto, Moreira e Sucena (2002), o grupo focal tratase de:

Uma técnica de pesquisa na qual o Pesquisador reúne, num mesmo local e durante certo período, uma determinada quantidade de pessoas que fazem parte do público-alvo de suas investigações, tendo como objetivo coletar, a partir do diálogo e do debate com e entre eles, informações acerca de um tema específico (NETO; MOREIRA; SUCENA, 2002, p. 5). 
Dessa forma, a escolha de grupos focais para gerar o corpus de estudo se justifica, uma vez que essa opção diz respeito a um grupo de professores que se reúnem para desenvolver uma discussão focada em um tema específico, em que muitos pontos de vista podem ser discutidos por eles.

Com a intencionalidade focada no entendimento de como atuam no contexto da inserção de laptops, a discussão do grupo versou sobre as interlocuções que esse cenário trouxe para a escola nos aspectos da formação técnica, humana e pedagógica dos sujeitos envolvidos. Para isso, eles descreveram como ocorrem suas práticas, a relação com os estudantes e com os laptops, falando de suas percepções e de seus sentimentos.

As conversações foram conduzidas por um mediador que, mais do que dirigir ou induzir as falas no grupo, teve a função de intermediá-las, instigando trocas recursivas, construções e interlocuções. Essa postura permitiu que as falas dos sujeitos avançassem além das impressões individuais, entrelaçando-se, para que pudessem fazer sentido para os participantes.

Nesse cenário, falaram sem constrangimentos sobre suas práticas, suas dúvidas, suas inquietudes e inseguranças, e foram escutadas com sensibilidade, sem julgamentos e com aceitação, sendo, portanto, coerente com o que propõe Barbier (2002) sobre a escuta sensível, a qual se apoia na empatia, na medida em que permite que o pesquisador sinta o universo afetivo, imaginário e cognitivo do outro, passando, assim, a compreender seu sistema de ideias a partir de atitudes, comportamentos, valores e símbolos.

O desenvolvimento do grupo focal foi norteado por um roteiro de questões relacionadas ao tema a ser discutido que, por sua vez, tinha relação com a pergunta de pesquisa. Essas questões foram formuladas no sentido de incentivar os professores a discorrerem sobre suas práticas pedagógicas com a presença dos laptops, explicitando dúvidas, anseios, dificuldades e avanços, dentre outros elementos. Expondo suas angústias, suas incertezas, seus sucessos e suas realizações, instalou-se no grupo uma dinâmica de cumplicidade e de compartilhamento. 
Ao principiarmos, sugerimos que os sujeitos se apresentassem, omitindo o nome, mas ressaltando aspectos como tempo de serviço na escola e área de atuação. Como instigação inicial, propusemos que cada componente escrevesse numa folha a palavra que, no seu entendimento, remetesse a um aspecto e/ou emoção relacionada à inserção dos laptops na escola.

A seguir, as folhas foram colocadas no chão, no interior do círculo, de forma a serem visíveis por todos. Dando prosseguimento, propusemos que cada um falasse sobre a palavra que trouxe ao grupo, bem como sobre a dinâmica que as palavras - a sua e as dos outros componentes do grupo - traz para o trabalho em sala de aula.

As palavras apresentadas pelos sujeitos foram: inovação, busca, avanços/perdida, avanços, mudança, transformação. Elas desencadearam a conversação. Seguimos, norteadas pelas questões que serviram como fio condutor da entrevista, relacionadas a facilitadores e dificultadores que a presença dos laptops introduz no cenário da escola, nas práticas vigentes e nas relações entre os sujeitos envolvidos. Finalizando a conversação, cada participante teve a oportunidade de expressar-se de forma livre, avaliando ou comentando a atividade desenvolvida.

O grupo focal teve duração de uma hora e trinta minutos, e foi registrado por meio de gravação, com consentimento dos participantes, que também assinaram Termo de Consentimento Esclarecido. Informamos os objetivos da pesquisa aos participantes, justificando a necessidade de gravação e assegurando o resguardo do sigilo.

Os dados foram transcritos para compor o corpus, que foi tratado segundo a análise textual discursiva proposta por Moraes e Galiazzi (2007). Assim, em movimentos de inda e de vinda do corpus, tendo a teoria como norteadora e a pergunta de pesquisa como fio condutor, foram realizados movimentos de desconstrução, o que esses autores denominam de caos, pois permite perceber os sentidos dos textos no limite do rompimento da ordem existente, tornando caótico o texto antes organizado. Desse movimento desconstrutivo, avançamos para a unitarização e, dela, para o processo de categorização, que culminou com a identificação de categorias emergentes, na busca por entender 
a dinâmica relacional dos professores em sua convivência diária, apreendida pelos seus registros no grupo focal.

O passo seguinte foi buscar as relações entre as categorias, na construção da resposta para a pergunta de pesquisa, descrevendo e explicando, por meio de inferências sustentadas pela teoria, o que as falas dos sujeitos permitem, uma vez que os sujeitos no grupo focal operaram com a linguagem sobre sua conduta. O descrever e o explicar a partir das categorias emergentes foi constituído por operações recursivas de ir e de vir do corpus e da teoria, com o objetivo de identificar mudanças na forma de atuar dos professores no contexto do estudo. Isso foi realizado sem juízos de valor, entendendo os sujeitos na sua maneira particular de viver e de ser, possível de ser apreendida a partir das verbalizações capturadas no grupo focal. Com o intuito de preservar o sigilo quanto à identidade dos sujeitos, eles foram nomeados de S1, S2, S3, S4, S5 e S6.

Informamos que os professores participantes assinaram Termo de Consentimento Livre e Esclarecido e que foram informados sobre a pesquisa em andamento. Também participaram de um seminário em novembro de 2015, no qual os resultados parciais deste estudo foram apresentados e discutidos com a presença das professoras gestoras da escola.

\section{Discussão: buscando entender as mudanças dos professores diante da inserção dos laptops}

No processo de unitarização do corpus, identificamos as seguintes categorias emergentes: aceitar o convite de conviver e de mudar, resistir à inserção do laptop em suas práticas e atuar, em parceria com os estudantes, na busca por alternativas para mudanças na prática.

\section{a) Aceitar o convite de conviver e de mudar}

Nessa categoria, foram consideradas verbalizações pelas quais os professores mostraram que se encontram dispostos a interagirem com outros sujeitos, numa convivência que potencialize a mudança no sentido de transformar práticas pedagógicas, permitindo, assim, o uso do 
laptop, interessando-se em participar das ações de formação e pensando em formas de incluir os laptops em suas aulas. Eles relataram que organizaram momentos de interlocuções, para pensarem a construção de práticas que incluíssem a presença do laptop.

Isso pode ser percebido nas seguintes falas:

Com a professora do laboratório de informática, a gente, eu planejo com ela, às vezes quando pego carona prá ir pro centro com ela ou às vezes assim na porta quando a gente se enxerga... (S2)

Então nós estamos com uma demanda e a gente está tentando se achar quem é o professor hoje. Às vezes eu fico me perguntando: quem é o professor hoje? O que é o professor hoje? Dentro de todo esse contexto que a gente está vivendo. Toda essa questão... (S5)

[...] não tenho receio de fazer uso... (das tecnologias) (S4)

[...] aquilo que nós trabalhamos nós não temos esses momentos prá trocar. Os momentos que nós fizemos trocas...[...] são os momentos, não é um momento específico, não é um momento que a escola te destina prá fazer (S2)

[...] a gente conversa assim, ó, nos corredores, quando a gente tá subindo (S2).

Essas verbalizações parecem denotar modificações congruentes, ou seja, mudanças ocorridas a partir do acoplamento com o ambiente modificado pela inserção dos laptops, por meio das interações com seus pares, buscando a ressignificação da realidade a partir da discussão, da apropriação e da busca por alternativas para se incluir o dispositivo nas práticas. Sob essa abordagem, podemos inferir sobre os sinais de mudanças nas práticas docentes, desencadeadas pelo redimensionamento da forma de atuar dos sujeitos envolvidos. Processos que parecem ser gerados pela estrutura interna de professores. Isso pode ser sustentado pelo momento em que, nas verbalizações, os professores fazem referência sobre pensarem o seu fazer, buscando rever suas aulas, em parceria com outros, repensando-as para incluir os dispositivos digitais.

Segundo Maturana (2002), é nesse fluir de ações na convivência que mudanças podem resultar de um processo de interações recorrentes. Aquilo que denominamos conduta no organismo não é algo que ele 
faz por si próprio e desde si, mas algo que emerge como um acontecer, que envolve sua dinâmica com a dinâmica do meio e com o outro num fluir congruente, que nada mais é do que um aspecto da autopoiese do seu organismo operando em acoplamento estrutural com o meio (MATURANA; DÁVILA, 2009).

Sob esse enfoque, as verbalizações indicam movimentos de autoobservação e de reflexão sobre a forma de agir, apresentados pelos professores, sugerindo um grupo comprometido com seu fazer, buscando novas formas de ser diante do novo, no caso, a presença da tecnologia digital, representada pelo laptop.

b) Resistir à inserção do laptop em suas práticas

Nessa categoria, encontram-se verbalizações que indicam a resistência em incluir o laptop nas práticas docentes, ou por dificuldade em se pensar alternativas ou por não perceber que essa inserção possa oferecer melhoria na aprendizagem. Parece, nesses casos, que o professor não se deixou afetar pela demanda da inserção digital, mostrando-se pouco perturbado por isso. Em algumas verbalizações, os professores parecem demonstrar que esperaram um roteiro para realizar as mudanças.

Algumas verbalizações indicam que os professores atuam como se as ações de se pensar em alternativas para o uso do laptop estivessem fora de seu domínio; sendo assim, eximem-se de assumirem responsabilidade sobre os processos de sua inserção, transferindo-a para agentes externos:

Só que assim, ó, eu acho que a gente aprende pouco a trabalhar com alunos (S4).

[...] e que a gente se troque mais as experiências. Eu acho que é uma questão de organização que a gente não consegue, não aprendeu muito específico. Todo mundo fala: mas é questão de tempo (S1).

Se não tivesse a professora do laboratório de informática, eu jamais teria feito história em quadrinhos, porque eu não sabia aonde procurar a história em quadrinhos (S1).

É muito complicado isso. Eu não vi isso, eu não sei aonde é que eu faço isso. [referindo-se ao fato de não encontrar um dispositivo para 
construir histórias em quadrinhos com os alunos] (S2).

Importante ressaltar que essa forma de atuar é legítima. Ela pode indicar que as demandas advindas da inserção digital na escola não afetaram a estrutura de alguns professores. No entanto, um sujeito que esteja num domínio pode ser afetado por ele. Sob essa abordagem, parece-nos que a aparente resistência também se insere no contexto das mudanças de práticas, pois os sujeitos que a sinalizam, por estarem inseridos no contexto em processo de mudança, na interação recorrente com o meio, podem encontrar alternativas para com elas conviverem.

Mesmo denotando resistência, ao afirmarem que "é muito complicado" e que "a gente não consegue", os sujeitos que verbalizam tais asserções encontram-se num ambiente denominado nicho, conforme Maturana e Dávila (2009). Assim, ao viverem em coerência operacional com esse meio, podem ser, por ele, afetados:

A realização do viver de um organismo em coerência operacional com seu nicho, tanto como a realização e a conservação da unidade relacional organismo/nicho, ocorre na dinâmica da unidade da arquitetura variável que o organismo e seu nicho constituem juntos na medida em que suas interações recursivas têm como resultado a conservação de sua coerência operacional no curso de suas mudanças arquitetônicas independentes, enquanto o organismo conserva seu viver (MATURANA; DÁVILA, 2009, p. 106).

c) Atuar em parceria com os estudantes na busca por alternativas para mudanças na prática.

Nessa categoria, estão as verbalizações que mostram movimentos de atuação, em parceria com os estudantes, para encontrar formas de incluir os laptops nas aulas. Nesse sentido, parece que a presença do laptop desencadeou a constituição de redes interativas, nas quais os estudantes atuam em parceria com o professor, auxiliando-o no que diz respeito aos desafios que a tecnologia impõe:

E quem trabalha, que acaba tendo uma facilidade maior para trabalhar são os adolescentes, então me recordo que uma tarde os alunos acabaram me auxiliando aos caminhos do uso da 
ferramenta. [...] então, na verdade, as coisas se movimentam, assim, não digo que se confundem, mas os alunos têm esse conhecimento maior destas ferramentas da área do software (S4).

Quando eles, os professores, se organizam com seus pares, na busca por alternativas para incluir os laptops na sua prática, quando buscam a parceria dos estudantes, inserem-se em outro domínio, agora de responsabilidade e de independência. Ao operar em congruência com seu meio, os sujeitos, no caso, professores e alunos, modificam-se de forma congruente com sua atuação, atuando num domínio de interdependência.

Conforme Maturana (2002), os seres vivos são sistemas determinados estruturalmente, e sua conduta resulta de sua dinâmica estrutural, sendo determinada por ela, de forma que os objetos externos podem somente ser perturbadores desses sistemas, desencadeando mudanças estruturais determinadas pela sua própria estrutura. Dessa forma, mudanças precisam ser resultados de reorganizações de dinâmicas internas na estrutura do organismo, que seleciona o que é ou não relevante para ele.

No caso de nosso estudo, esse agente externo é a inserção digital no cotidiano escolar, que parece estar provocando mudanças estruturais, perceptíveis através das verbalizações de professores, quando relatam que estão atuando e refletindo sobre sua ação, revendo suas práticas e pensando em novas alternativas. Assim, inferimos que eles estão se modificando e ressignificando sua ação frente à presença do laptop e das demandas advindas disso.

Também inferimos que a circunstância da escola, modificada pela inserção do laptop, é um meio capaz de produzir mudanças na estrutura dos sujeitos que, por sua vez, agem sobre ela, alterando-o, numa relação circular: acoplamento estrutural. Assim, professores e ambiente se modificam mutuamente, em interações recorrentes, de forma que o estar juntos se constitui num acoplamento cuja conduta de um deles está ligada, de alguma forma, à do outro, numa rede de coordenações de ações (MATURANA, 2002).

Seguindo o caminho dessas considerações, podemos concluir que os professores vivem mudanças em sua prática. Embora alguns ainda estejam dependentes de uma formação que lhes indique formas de 
atuar, a visão da Biologia do Conhecer nos permite inferir que ambas são legítimas, pois retratam momentos diferentes de um mesmo fluxo de movimento de perturbação, desencadeado pela presença do laptop. Conforme Maturana (2001), as redes de conversações que configuram o aprender e o viver se constituem na convivência pela linguagem. Esta convivência precisa ser recursiva, em coordenações de ações, para que seja possível aos professores se modificarem no operar constitutivo de suas práticas.

Quando os professores buscam formas de repensar suas práticas, aceitam a parceria de seus alunos nesse processo; estão inseridos num domínio de convivência e de reorganização, o que pode ser sinal de emergência de movimentos de auto-organização. Movimentos estes precursores da constituição de uma forma de atuar entre eles e seus estudantes, em acoplamento estrutural.

Como "observadores implicados" (MATURANA, 2001), os professores pensam sobre seu pensar e sobre o processo, naquilo que Pellanda (2009) se refere como atitude metacognitiva e potencializadora, uma vez que capacita os sujeitos a uma complexificação crescente, posto que o observador implicado observa a si mesmo operando no sistema. Aprofundando sua reflexão, a autora destaca que "a realidade emerge com a ação do observador" (PELLANDA, 2009, p. 26), o que, nesse caso, está relacionado ao observar a própria ação de redimensionar a prática, considerando a presença dos laptops, buscando uma nova realidade para a sala de aula que contemple tal presença.

Frente a essas considerações, os sinais de redimensionamento das práticas na inserção digital parecem ter surgido da observação de si próprio, num processo de autoconhecimento, e da convivência com os estudantes e com o laptop, em acoplamento estrutural. O que permite concluir que, quando professores se observam e pensam sobre os próprios processos de ser professor, nesse cenário, observando seu operar em acoplamento com o outro, com os estudantes e com a tecnologia, eles se modificam, em congruência com seu operar e em acoplamento com seu domínio de ação.

Schlemmer (2010) se refere a essa forma de buscar novas maneiras 
de atuar, incluindo as tecnologias digitais nas práticas pedagógicas, como uma relação pela qual estudantes e professores se constituem coensinantes e coaprendentes, num processo que ela chama de intermediação pedagógica múltipla e relacional, num conviver digital em que a transformação mútua é o resultado de interações que levam a um diálogo autêntico.

\section{Considerações finais}

Compartilhamos resultados de uma pesquisa cujo objetivo era entender como os professores estão modificando suas práticas, num cenário escolar alterado pela presença de laptops na modalidade 1:1, numa escola municipal de ensino fundamental. Para isso, tomamos como corpus de estudo dados constituídos por verbalizações de professores, por meio de entrevista com grupo focal.

A análise das categorias emergentes permite inferir que estão acontecendo movimentos de auto-observação e de reflexão por parte dos professores, num fluxo de interações recorrentes, a fim de reorganizarem suas práticas. Fluxos ancorados em ações de auto-observação e de autoconhecimento, em convivência com os estudantes e com o laptop. Isso permite concluir que, quando professores se observam e pensam sobre os próprios processos de ser professor, nesse cenário, observando seu operar, em acoplamento com os estudantes e com a tecnologia, eles se modificam, em congruência com seu operar e em acoplamento com seu domínio de ação.

Dito de outra forma, as mudanças que ocorrem na prática docente, com a inserção de laptops, são resultados de fluxos de interações entre estudantes e professores, sustentadas por discussão e reflexão sobre o fazer pedagógico e as possibilidades advindas dos recursos da tecnologia digital num processo recursivo. Assim, professores e estudantes, juntos, renovam-se e transformam-se, geram e regeneram o próprio sistema de conviver, por meio de ideias e questionamentos.

Esse operar parece ocorrer num contexto de ações compartilhadas: da apropriação de novos conceitos e de reflexões em que cada professor 
realiza um esforço para a construção de consensualidade, na busca por se apropriar da tecnologia, modificando o seu fazer pedagógico, em seu próprio território de experiências já vivenciadas, construindo, assim, novos domínios de prática docente. Essa afirmação é sustentada por Maturana e Dávila (2009), quando enfatizam que: “Tudo o que um observador faz como ser vivo e ser humano surge em seu fazer de acordo com regularidades e coerências operacionais que se conservam em todos os instantes e circunstâncias de seu operar no fluir da realização de seu viver. Não há acaso no suceder do viver" (MATURANA; DÁVILA, 2009, p. 119).

Essa convivência parece mostrar o professor considerado, desde seu lugar, como sujeito que existe numa rede de relações, compreendendose como ser humano, a partir de suas crenças, de seus anseios e de suas formas de ser. Desse lugar, parece que ele pode ver o estudante como seu parceiro na convivência da sala de aula, agora ampliada pelas possibilidades do laptop. A partir do momento em que o dizer de um sujeito encontra ressonância no sentir e no fazer do outro é que a convivência pode acontecer, e daí ambos podem se transformar em congruência. Sob essa abordagem, a convivência se faz em cada um, como cocriador de um espaço humano de convívio social desejável, entendido no sentido do compartilhar, em que o outro não seja negado na relação como ser, mas aceito em sua legitimidade (MATURANA; REZEPKA, 2000).

Dos resultados que apresentamos, podemos inferir que o redimensionamento das práticas docentes no contexto da inserção digital precisa se alicerçar em conversações na convivência. Ao compartilhar suas dúvidas e incertezas, dificuldades encontradas no cotidiano de um fazer estranho às práticas usuais - professor/quadro-negro $X$ aluno/ caderno - é que os educadores terão a possibilidade de construir um novo fazer pedagógico. Isso está em concordância com o que apresentam Maturana e Dávila (2009), quando eles afirmam: 
Nosso viver humano ocorre no fluir relacional de nosso conviver no linguajear entrelaçado com nossas emoções em redes de conversações, como âmbitos de coordenações de coordenações de fazeres e emoções nos quais podemos ser conscientes do que fazemos e conversar sobre nosso viver e conviver (MATURANA; DÁVILA, 2009, p. 219).

Em outras palavras, somos humanos ao nos constituirmos pela linguagem, e, através dela, mantemos e configuramos nosso viver, que é sempre relacional. De tal forma que egoísmo, individualismo e personalismo - emoções usuais em espaços denominados pelo autor como não sociais - nos afastam, como espécie, do sentido de ser, pois configuram domínios de ação a partir da negação do outro (MATURANA, 2001). É a convivência na conversação que nos mantém como espécie. O conversar liberador, através do qual a escuta sensível e o respeito ao falar do outro pressupõem um ato de humildade na convivência, possibilita construir a liberação das inquietudes que subjazem as atitudes cotidianas de ser professor no cenário digital contemporâneo.

A arte do conversar liberador, que abre caminho de saída para a dor e o sofrimento cultural, está em saber como olhar a matriz relacional que realiza, conserva e gera mal-estar no próprio viver e conviver, e, assim, descobrir, em conjunto com a pessoa que solicita ajuda, a forma da negação cultural que gerou esse mal-estar em seu viver (MATURANA; D'AVILA, 2009, p. 239).

O mal-estar referido pelos autores se funda em questionamentos que povoam o cotidiano do professor, na inquietude de não saber com o que estão lidando: como dar conta dessa nova realidade que se constitui de múltiplas interfaces: saberes, convivência, tecnologia? De que forma organizar a aula, a fim de permitir o diálogo, a cooperação, a colaboração dos participantes, constituindo a dinâmica do aluno sujeito da aprendizagem, no sentido da construção da autonomia? Sob esse ponto de vista, reafirmamos, conforme Maturana (1997), que as escolas, como espaço de convivência na diversidade, precisam permitir o exercício cotidiano de aceitar o outro como legítimo outro. Este princípio, para o autor, define o amor como a emoção que nos constitui humanos. 
Sob essa forma de entender o cotidiano de atuação entre professores e alunos, convivendo-se na inserção digital, pode-se considerá-lo como sistema vivo, um domínio no qual esses sujeitos podem se modificar de forma congruente, em que o meio produz mudanças em suas estruturas que, por sua vez, agem sobre eles, alterando-os, numa relação circular: o acoplamento estrutural.

Assim, os resultados encontrados nos mostram que a transformação do domínio de ação nas escolas, permeado pelas tecnologias digitais, é sustentado pelas ações de seus interagentes (estudantes e professores), de forma congruente, numa relação circular e auto-organizada por meio de suas interações recorrentes. Ações baseadas no respeito mútuo, na escuta dos anseios e dos receios, na aceitação do outro como legítimo outro em seu pensar, levando em conta a heterogeneidade que existe em uma sala de aula, tomando esses aspectos como promotores do enriquecimento e da inovação do processo de ensino e de aprendizagem.

Encerramos dizendo que as mudanças que pudemos perceber a partir das narrativas dos professores aconteceram como consequência do acoplamento estrutural desses sujeitos, fluindo em seu espaço escolar com seus estudantes e com seus colegas de docência. Assim, aceitaram o desafio de conviver transitoriamente entre si e com as possibilidades do laptop, em coordenações de ação e de reflexão, aceitando-se mutuamente como legítimos seres em convivência.

\section{Referências}

BARBIER, R. Escuta sensível na formação de profissionais de saúde. Conferência na Escola Superior de Ciências da Saúde. Brasília: Secretaria do Estado de Saúde do Distrito Federal, 2002. Disponível em: <http:/ / www.barbierrd.nom.fr/ESCUTASENSIVEL.PDF>. Acesso em: 24 mai. 2013.

BEILER, A. A produção de redes de conversação como base à aprendizagem. 2004. Tese (Doutorado em Informática na Educação) - Departamento de Psicologia, Instituto de Informática, Faculdade de 
Educação, Universidade Federal do Rio Grande do Sul, Porto Alegre, 2004.

FAGUNDES, L. C.; VALENTINI, C. B.; SOARES, E. M. S. Linguagem, educação e recursos midiáticos: quem mexeu na minha escola? In: PESCADOR, C.; SOARES, E. M. S.; NODARI, P. C. (Org.). Ética, educação e tecnologia: pensamento em alternativas para os desafios da educação na atualidade. Curitiba: Editora CRV, 2010.

LOPES, D. Q.; VALENTINI, C. B. Mídias locativas e realidade mixada: a produção de sentidos sobre o digital-virtual a partir da cartografia com suporte das tecnologias digitais. Educação Unisinos, São Leopoldo, RS, v. 16, p. 205-214, 2012.

MARASCHIN, C.; AXT, M. Acoplamento tecnológico e cognição. In: VIGNERON, J.; OLIVEIRA, V.B. de (Org.). Sala de aula e tecnologias. São Bernardo do Campo, SP: Universidade Metodista de São Paulo, 2005. p. 39-51.

MATURANA, H. R. Uma nova concepção de aprendizagem. Dois pontos, Belo Horizonte, v. 2, n. 15, p. 28-35, jan./jul. 1993.

. A ontologia da realidade. Belo Horizonte: UFMG, 1997.

Cognição, ciência e vida cotidiana. Belo Horizonte: UFMG, 2001.

. Transformação na convivência. Santiago do Chile: Dolmen Ediciones, 2002.

MATURANA, H. R.; DÁVILA, X. Y. Habitar humano em seis ensaios de biologia-cultural. São Paulo: Palas Athena, 2009.

MORAES R.; GALIAZZI, M. C. Análise textual discursiva. Ijuí, RS: Unijuí, 2007. 
NETO, O. C.; MOREIRA, M. R.; SUCENA, L. F. M. Grupos focais e pesquisa social qualitativa: o debate orientado como técnica de investigação. In: ENCONTRO DA ASSOCIAÇÃO BRASILEIRA DE ESTUDOS POPULACIONAIS, 13., 2002, Ouro Preto, MG. Anais... Ouro Preto, MG: ABEP, 2002.

PELLANDA, N. M. C. Maturana \& a educação. Belo Horizonte: Autêntica, 2009.

SCHLEMMER, E. Formação de professores na modalidade on-line: experiências e reflexões sobre a criação de espaços de convivência digitais virtuais. Em Aberto, Brasília, v. 23, n. 84, p. 99-122, nov. 2010.

SOARES, E. M. S.; LUCIANO, N. A. Formação continuada de professores no contexto das tecnologias digitais. In: CONGRESSO INTERNACIONAL DE EDUCAÇÃO A DISTÂNCIA, 11., 2004 Salvador. Anais... Salvador: ABED, 2004. Disponível em: <http:/ / www.abed.org.br/congresso2004/ por/gradetc.htm>. Acesso em: 29 jul. 2010.

SOARES, E. M. S.; VALENTINI, C B; PESCADOR, C M. O laptop educacional na escola pública: letramento digital e possibilidades de transformação das práticas pedagógicas. Educação, Santa Maria, RS, v. 38, n. 1, p. 151-164, jan./abr. 2013.

SOARES, E. M. S.; VALENTINI, C. B. PROUCA no Brasil: socializando resultados de pesquisas: inserção de laptop na modalidade 1:1, da inserção à inclusão: letramento digital e construção de significados. In: SEMINÁRIO AULAS CONECTADAS: INOVAÇÃO CURRICULAR E APRENDIZAGEM COLABORATIVA NO ENSINO BÁSICO, 2., 2013, Florianópolis. Anais... Florianópolis: FAED/UDESC, 2013.

Recebido em 08/05/2016 Aprovado em 15/07/2016 